\title{
PRODUÇÃO DE ALFACE AMERICANA EM SUCESSÃO A PLANTAS DE COBERTURA
}

\author{
Lílian Moreira Costa ${ }^{1}$, Everton Oyama Iocio $^{2}$, José Weselli de Sá Andrade ${ }^{3}$ \\ ${ }^{1}$ Mestre em Ciências Agrárias, email: lilian22moreira@gmail.com \\ ${ }^{2}$ Engenheiro Agrônomo, email: evertonoyama@ hotmail.com \\ ${ }^{3}$ Professor Doutor em Agronomia, email: weselli@ibest.com.br \\ Instituto Federal de Educação, Ciência e Tecnologia Goiano - Campus Rio Verde - GO.
}

RESUMO: Objetivou-se com esse trabalho avaliar a produção de massa seca de plantas de cobertura, e seu efeito na produção da alface. O experimento foi conduzido no Setor de Olericultura do Instituto Federal Goiano, Campus Rio Verde, GO, em Latossolo Vermelho distrófico. O delineamento experimental foi blocos ao acaso, com seis tratamentos e quatro repetições: vegetação espontânea; guandu + brachiaria; guandu + milheto; crotalária + brachiaria; crotalária + milheto; adubação nitrogenada. Para implantação do experimento procedeu-se o preparo convencional da área com aração e gradagem, em seguida, os canteiros foram levantados com microtrator e enxada rotativa. A semeadura das plantas de cobertura em consórcio foi realizada manualmente de forma intercalar no mesmo sulco de plantio na profundidade de $2 \mathrm{~cm}$, com 2 linhas espaçadas de $25 \mathrm{~cm}$. Avaliou-se a produção de massa seca das plantas de cobertura, aos 55 dias após a semeadura. Para a cultura da alface, avaliou-se a massa fresca e seca da parte aérea. Os resultados mostraram que o consórcio crotálaria + milheto se destacou com maior produção de massa seca, e conferiu maior produção de massa fresca da alface, o que mostra a viabilidade do uso desse consórcio em substituição à adubação mineral.

Palavras-chave: Adubação verde. Massa seca. Lactuca sativa.

\section{AMERICAN LETTUCE PRODUCTION IN SUCCESSION TO COVERING PLANTS}

\begin{abstract}
This work aimed to evaluate dry biomass production of covering plants, and its effect on American lettuce production. The trial was carried out at the Sector of Horticulture from Instituto Federal Goiano, Campus Rio Verde, GO, in an Oxisol. The experimental design was randomized blocks, with six treatments and four replicates: spontaneous vegetation; pigeonpea + brachiaria; pigeonpea + millet; crotalaria + millet; nitrogen fertilization. To install the trial, the area was conventionally prepared with plowing and harrowing, and sequent, the beds were raised with micro tractor and rotary tiller. The sowing of covering plants in consortium was done manually in interim order in the same furrow at $2 \mathrm{~cm}$ depth, with two rows spaced $25 \mathrm{~cm}$. Dry biomass production of covering plants was evaluated at 55 days after sowing. Fresh and dry mass of shoots were evaluated. The results showed that the consortium crotalaria + millet stood out with higher production of dry matter, and conferred higher fresh mass production, what shows the viability of using
\end{abstract}


that consortium in substitution to mineral fertilization.

Key words: Green manuring. Dry mass. Lactuca sativa.

\section{INTRODUÇÃO}

A adubação verde pode ser definida como a utilização de plantas em rotação, sucessão ou consorciação com outras, sendo incorporadas ao solo ou deixadas na superfície, visando à proteção superficial, bem como à manutenção e melhoria das características físicas, químicas e biológicas do solo, levando a cultura subsequente a se beneficiar destas mudanças, refletindo normalmente em maiores produtividades (NEGRINI, 2007).

Teodoro et al. (2009), avaliaram leguminosas quanto à produção de fitomassa da parte aérea e quanto ao acúmulo de macronutrientes. Constataram que essas espécies acumulam considerável massa de $\mathrm{N}, \mathrm{P}$ e $\mathrm{K}$, na seguinte ordem: $\mathrm{N}>\mathrm{K}>\mathrm{P}$.

Assim há grande perspectivas de utilização da adubação verde para garantia de produtividade; de preservação ambiental; poupança de insumos, principalmente adubos nitrogenados, e o adubo verde é importante, sobretudo pelo auxílio na recuperação da fertilidade do solo e controle da erosão (AMBROSANO et al, 2011). As plantas da família das Leguminosas (ou Fabaceae) são as mais utilizadas como adubo verde. De acordo com Silva e Menezes (2007), a principal razão para essa preferência está em sua capacidade de simbiose com bactérias fixadoras do $\mathrm{N}_{2}$ atmosférico. $\mathrm{O}$ autor cita também a rusticidade, à elevada produção de matéria seca e ao sistema radicular geralmente profundo e ramificado, capaz de extrair nutrientes das camadas mais profundas do solo.

A produção de hortaliças como a alface necessita de grandes quantidades de fertilizantes, principalmente para o fornecimento de nitrogênio. Nesse sentido, a utilização de plantas de cobertura como fonte para nutrientes e de proporcionar adequada nutrição das hortaliças é uma importante alternativa para o bom desenvolvimento da cultura. Assim, objetivou-se no presente trabalho avaliar a produção de massa seca de quatro espécies de adubos verdes, e da vegetação espontânea, quanto ao seu efeito na produção da alface.

\section{MATERIAL E MÉTODOS}

O trabalho foi conduzido no setor de Olericultura do IF Goiano - Campus de Rio Verde, GO. O solo da área experimental é classificado em Latossolo Vermelho distrófico, e para fins de caracterização do solo, foram coletadas amostras na profundidade de $0-5 ; 5-10$ e 10-20cm (Tabela 1 e 2).

Inicialmente, estabeleceram-se os tratamentos com plantas de cobertura em précultivo à cultura da alface. $\mathrm{O}$ delineamento experimental foi em blocos ao acaso com seis tratamentos e quatro repetições. Os tratamentos foram: T1- vegetação espontânea; T2 feijão guandu (Cajanus cajan) + braquiária (Brachiaria brizantha); T3 - feijão guandu + 
milheto (Pennisetum americanum); T4 - crotalária (Crotalária juncea) + braquiária; T5 crotalária + milheto; T6 - adubação com sulfato de amônio no sulco de plantio.

Tabela 1. Resultados da análise química do solo amostrado na área experimental no IF Goiano - Campus de Rio Verde, GO, 2011.

\begin{tabular}{|c|c|c|c|c|c|c|c|c|c|c|}
\hline $\begin{array}{l}\text { Profundida } \\
\text { de } \\
\mathrm{cm}\end{array}$ & $\begin{array}{c}\mathrm{pH} \\
\left(\mathrm{H}_{2} \mathrm{O}\right)\end{array}$ & $\mathrm{Ca}^{2+}$ & $\mathrm{Mg}^{2+}$ & $\mathrm{Al}^{3+}$ & $\begin{array}{c}\mathrm{H}^{+}+\mathrm{Al}^{3+} \\
\mathrm{l}_{\mathrm{c}} \mathrm{dm}^{-3} \ldots . .\end{array}$ & $\mathrm{K}^{+}$ & CTC & $\begin{array}{c}\mathrm{P} \\
\mathrm{mg} \mathrm{dm}^{-3}\end{array}$ & $\begin{array}{l}\mathrm{V} \\
\%\end{array}$ & $\begin{array}{l}\text { M.O. } \\
\text { g Kg }^{-1}\end{array}$ \\
\hline $0-5$ & 6,40 & 4,8 & 1,36 & 0,00 & 5,94 & 0,2 & 12 , & 49,36 & 52,25 & 37,31 \\
\hline $5-10$ & 6,00 & 3,7 & 1,0 & 0,0 & 7,42 & 0, & 12 & 40 & 40,31 & 40,40 \\
\hline $10-20$ & 5,60 & 2,60 & 0,76 & 0,00 & 6,93 & 0,18 & 10,47 & 27,38 & 33,81 & 34,82 \\
\hline
\end{tabular}

Tabela 2. Resultados da análise física do solo amostrado na área experimental no IF Goiano - Campus de Rio Verde, GO, 2011.

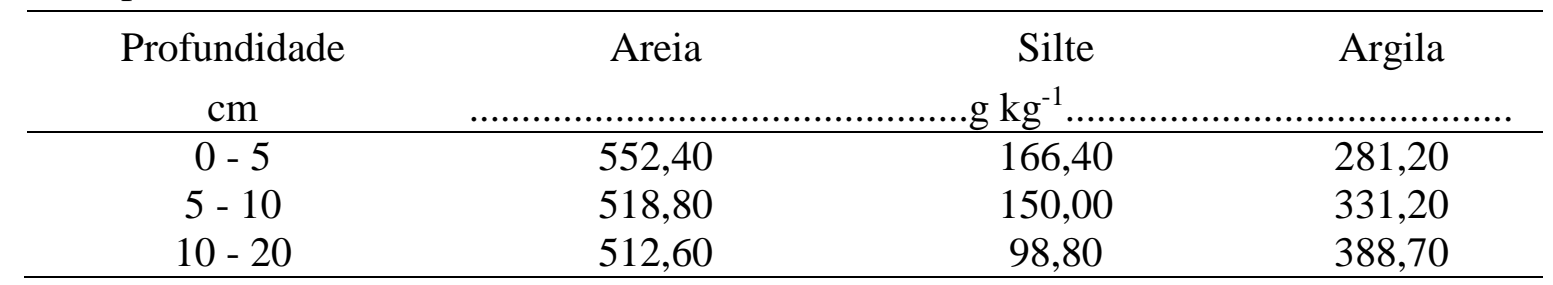

Utilizou-se uma área de $252 \mathrm{~m}^{2},(21 \times 12 \mathrm{~m})$ dividida em 24 parcelas de 1,21 $\mathrm{m}^{2}(1,10$ x 1,10m). Para a implantação do experimento procedeu-se o preparo convencional da área (aração e gradagem), em seguida, os canteiros foram levantados com auxílio de microtrator e enxada rotativa, seguindo-se o sulcamento na profundidade de $2 \mathrm{~cm}$ com 2 linhas espaçadas de $25 \mathrm{~cm}$.

A semeadura dos consórcios entre fabacea e poacea foi realizado manualmente, na mesma linha de plantio, numa densidade de 30, 30, 25 e 25 sementes/m linear para crotalária, feijão guandu, milheto e braquiária, respectivamente. Foram realizadas capinas manuais, a cada 7 dias, de modo a evitar a competição de plantas daninhas e diariamente realizou-se suplementação hídrica com objetivo de fornecer umidade suficiente para o desenvolvimento das plantas de cobertura. A irrigação utilizada foi do tipo aspersão, sendo conhecido como Agropolo NY30 ERL, com uma vazão de $4,33 \mathrm{~m}^{3 / \mathrm{h}}$.

As plantas de cobertura foram tombadas com rolo faca e incorporadas no canteiro com auxílio de uma enxada rotativa, adotando-se o mesmo procedimento para a vegetação espontânea predominada principalmente por capim-pé-de-galinha (Eleusine indica) e trapoeraba (Commelina erecta).

No tratamento 6, utilizou-se o produto SULF-N ${ }^{\mathrm{T} M}$, que contém $21 \%$ de nitrogênio amoniacal $\left(\mathrm{N}_{-} \mathrm{NH}_{4}{ }^{+}\right)+24 \%$ de enxofre na forma de sulfato $\left(\mathrm{S}_{-} \mathrm{SO}_{4}{ }^{-2}\right)$. Essas características fazem do Sulfato de Amônio um adubo de ação rápida e eficiente, visto que o nitrogênio amoniacal e o enxofre na forma de sulfato são prontamente absorvidos pelas plantas. O Sulfato de Amônio somente foi utilizado no tratamento 6 na dosagem de $100 \mathrm{~kg} \mathrm{ha}^{-1}$,cuja incorporação no canteiro ocorreu no mesmo dia das plantas de cobertura.

As mudas para a alface foram produzidas em casa de vegetação, em bandejas de isopor de 200 células, contendo o substrato comercial Plantmax ${ }^{\circledR}$. O transplantio da alface

Cultura Agronômica, Ilha Solteira, v.24, n.2, p.157-166, 2015 
americana cultivar Grande Lagos 659, para os canteiros foi realizado 21 dias após a incorporação das plantas de cobertura. O espaçamento adotado para o transplantio da alface foi de 30 x $30 \mathrm{~cm}$, sendo a parcela experimental constituída de 10 plantas, dispostas em duas fileiras de 5, sendo utilizada a média para representar os respectivos tratamentos. Durante a permanência da alface nos canteiros foram realizados os tratos culturais recomendados para a cultura.

Aos 55 dias após a semeadura, foram retiradas duas amostras das plantas de cobertura nos tratamentos em consórcio, sendo uma amostra para poacea e outra para fabacea. Nos tratamentos 1 e 6 com vegetação espontânea foi coletada apenas uma amostra por parcela, para determinação da massa seca da parte aérea produzida na área. Para essa amostragem foi utilizado um quadrado de ferro de $30 \times 30 \mathrm{~cm}$ e as plantas de cobertura foram cortadas ao nível do solo. Após a coleta, as amostras foram acondicionadas em sacos de papel identificados e posteriormente foram colocadas para secar em estufa com circulação forçada de ar, mantendo-se a temperatura em $65{ }^{\circ} \mathrm{C}$ por 72 horas, até atingir massa constante, para quantificar a produção de massa seca da parte aérea das plantas. Essas amostras foram pesadas em uma balança analítica após estarem devidamente secas, e os resultados encontrados foram convertidos para $\mathrm{tha}^{-1}$.

Os parâmetros avaliados nas plantas de alface foram: massa (fresca e seca). A alface foi colhida 61 dias após a semeadura, onde foram coletadas cinco plantas de forma aleatória procurando-se amostrar plantas representativas de cada canteiro. As plantas foram cortadas logo abaixo das folhas basais, rentes ao solo, com auxílio de uma tesoura de ponta fina e depois foram acondicionadas em sacos de papel para determinação da massa fresca da parte aérea (cabeça), e posteriormente da massa seca, após permanecerem em estufa a $65^{\circ} \mathrm{C}$ por 96 horas.

A determinação do teor de pigmentos cloroplastídicos na alface foi realizada segundo metodologia descrita por Kuki et al. (2005). Foram coletados de cada repetição três discos foliares, retirados da terceira folha do ápice para a base, utilizando um furador de metal de 5 $\mathrm{mm}$ de diâmetro. Os discos foram incubados em frascos de vidro protegidos da luz por papel alumínio, contendo $5 \mathrm{~mL}$ do solvente orgânico dimetilsulfóxido (DMSO), totalizando 24 amostras. Esses frascos foram levados ao banho-maria à temperatura de $25^{\circ} \mathrm{C}$ por 24 horas. Após este período realizaram-se as leituras em espectrofotômetro Uv-visível, nas absorbâncias de $649 \mathrm{~nm}$ para clorofila b e $665 \mathrm{~nm}$ para clorofila a. Com os resultados das leituras, utilizaram-se as seguintes equações para determinar o conteúdo dos pigmentos fotossintéticos, de acordo com o proposto por Wellburn (1994):

[Clorofila $a$ ] $\left(\mu \mathrm{g} / \mathrm{cm}^{2}\right)=12,9 \mathrm{~A} 665-3,45 \mathrm{~A} 649$

[Clorofila $b$ ] $\left(\mu \mathrm{g} / \mathrm{cm}^{2}\right)=21,99 \mathrm{~A} 649-5,32 \mathrm{~A} 665$

[Clorofila total] $\left(\mu \mathrm{g} / \mathrm{cm}^{2}\right)=$ Clorofila $\mathrm{a}+$ Clorofila $\mathrm{b}$

Os resultados foram submetidos a análises de variância, utilizando-se o programa estatístico SISVAR (FERREIRA, 2007) e as médias foram comparadas pelo teste de Tukey a $5 \%$ de probabilidade.

Cultura Agronômica, Ilha Solteira, v.24, n.2, p.157-166, 2015 


\section{RESULTADOS E DISCUSSÃO}

Observando-se a figura 1 pode-se concluir que houve diferença significativa em relação ao rendimento de massa seca das plantas de cobertura da parte aérea. No entanto não houve diferença significativa entre os tratamentos 1 e 6 . O consórcio crotalária + milheto foi o que mais se destacou com uma produção de $\left(3,210 \mathrm{t} \mathrm{ha}^{-1}\right)$, deste consórcio a crotálaria contribui com 55\% da massa seca. De acordo com Perin et al. (2004), a menor produção de massa seca do milheto, no consórcio com a crotalária, pode ser atribuída à competição por recursos naturais, principalmente luz, pois a crotalária apresenta rápido estabelecimento e maior taxa inicial de crescimento, comparativamente ao milheto.

A produção de massa seca do milheto obtida nesse experimento $\left(2,918 \mathrm{t} \mathrm{ha}^{-1}\right)$, se comparada com as obtidas em outros estudos, foi baixa, a exemplo do verificado por Oliveira et al. (2002) que, com semeadura das plantas de cobertura em novembro, verificaram para o milheto, 100 dias após sua semeadura, rendimentos de massa seca de aproximadamente $14 \mathrm{tha}^{-1}$.

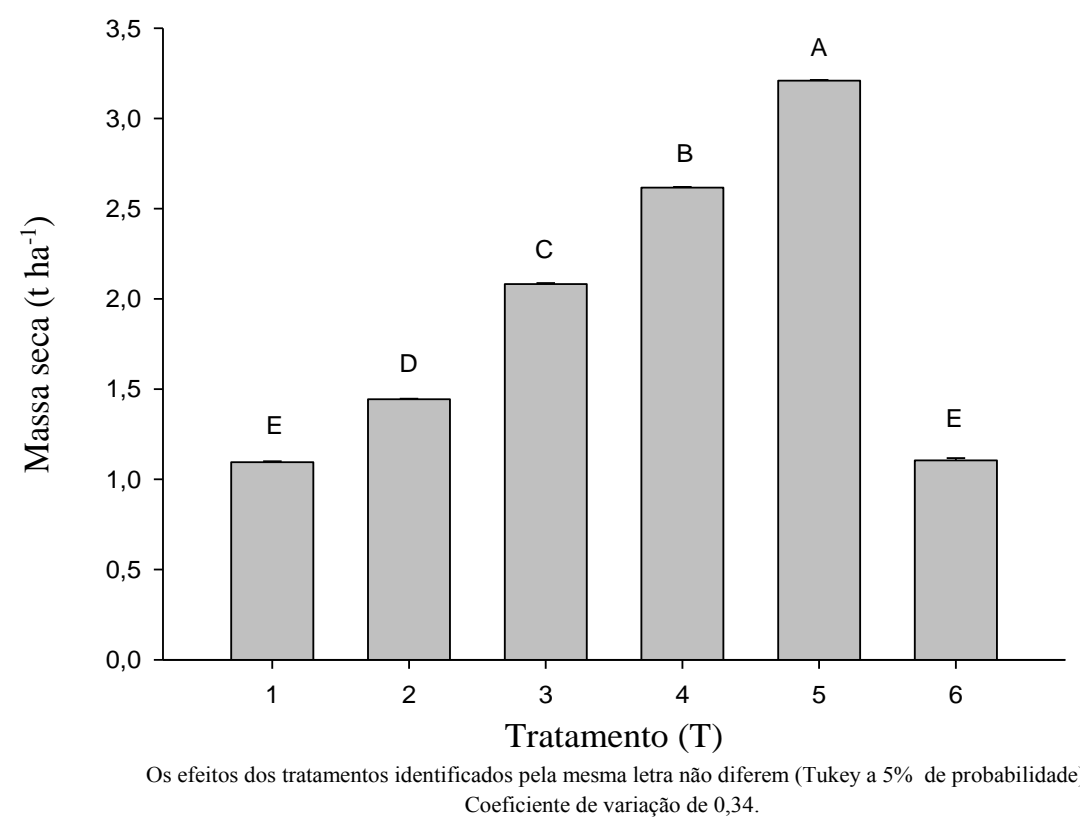

Figura 1. Massa seca das plantas de cobertura, colhida aos 55 dias após a semeadura, T1Vegetação espontânea; T2-Guandu + braquiária; T3-Guandu + milheto; T4-Crotalária + braquiária; T5-Crotalária + milheto; T6-Adubação com Sulfato de Amônio.

Segundo Netto e Bonamigo (2005), o milheto é bastante sensível ao fotoperíodo de dias curtos, ou seja, no fim do verão e início do outono, com a redução do comprimento dos dias, há indução floral e as plantas de milheto entram na fase reprodutiva. No consórcio com a crotalária, e guandu, a massa seca do milheto foi de $\left(2,873 \mathrm{t} \mathrm{ha}^{-1}\right)$ e $\left(2,918 \mathrm{t} \mathrm{ha}^{-1}\right)$, respectivamente. Esses resultados mostram que a semeadura intercalar de uma poacea de maior taxa de crescimento inicial, com outra espécie de crescimento relativamente mais lento (feijão guandu), pode ter favorecido o crescimento do milheto.

Cultura Agronômica, Ilha Solteira, v.24, n.2, p.157-166, 2015 
Portanto, cultivos consorciados envolvendo espécies de crescimento inicial relativamente lento, como o feijão guandu em associação a outras de alta capacidade de cobertura do solo como o milheto dependendo das condições edafoclimáticas e de manejo, provavelmente resultarão em plantas dominadas por parte das espécies mais lentas, desfavorecendo o equilíbrio na constituição da massa seca e prejudicando os benefícios almejados para a cultura de cobertura consorciada (CALVO, 2010).

No consórcio guandu + braquiária, a produção de massa seca da braquiária correspondeu a 57\% da massa seca total, com uma produção de $\left(1,67 \mathrm{t} \mathrm{ha}^{-1}\right)$. A braquiária por apresentar crescimento rápido e intenso se comparado ao feijão-guandu, contribuiu com a maior parte de massa seca produzida no consórcio. Segundo Kissmann, (1997), a braquiária é considerada como uma planta infestante, pois apresenta alta eficiência na utilização de recursos, o que confere sua agressividade na colonização do ambiente. A produção de massa seca do guandu obtida nesse experimento $\left(1,26 \mathrm{t} \mathrm{ha}^{-1}\right)$, se comparada com as obtidas em outros estudos, foi baixa, a exemplo do verificado por Carvalho et al. (2004), que obtiveram, na média de dois anos, para o feijão guandu semeado em novembro e manejado 60 dias depois da emergência, massa seca de 2,478 $\mathrm{t} \mathrm{ha}^{-1}$ na região de Selvíria, MS.

Desenvolvendo trabalho com o intuito de verificar a produção de massa verde e seca de diferentes plantas de cobertura, entre as quais o feijão guandu em um Latossolo Vermelho distrófico típico argiloso, no Município de Selvíria, MS, Suzuki e Alves (2006), constataram que o guandu obteve a menor produção de massa seca que foi de $6,46 \mathrm{tha}^{-1}$.

Essa baixa produção de massa seca do guandu, provavelmente ocorreu por causa do curto período de crescimento utilizado no presente experimento, (55 DAS), resultando em pouco tempo para o acúmulo de massa seca. Para o guandu, por exemplo, seria necessário um período bem maior (florescimento pleno aos 140-180 dias após emergência) para que a planta expressasse o seu potencial produtivo, pois Alvarenga et al. (1995), afirmam que as plantas de ciclo mais longo possuem a tendência de produzir maior quantidade de biomassa.

A crotalária apresentou resposta semelhante quanto à produção de massa seca em ambos os consórcios com acúmulo de massa seca de $\left(3,585 \mathrm{t} \mathrm{ha}^{-1}\right)$, inferior ao encontrado por Fontanétti (2006), que foi de 12,75 $\mathrm{t} \mathrm{ha}^{-1}$ para massa seca, em Lavras, MG, com plantio em dezembro e colheita aos 99 DAS. Esses rendimentos relatados em outros trabalhos mostram o potencial de produção de massa seca por algumas plantas de cobertura, quando obtido em um período de desenvolvimento maior.

De uma maneira geral, a escolha das espécies de fabaceas que apresentam rápido desenvolvimento inicial, tolerância ao Al tóxico, sistema radicular profundo, produção de fitomassa suficiente para a cobertura do solo, e a relação $\mathrm{C} / \mathrm{N}$ apropriada às culturas subsequentes é que favorecerá o grau de sucesso obtido com a utilização dessa prática (FERNANDES et al., 1999).

Esses resultados apresentados no experimento podem ser explicados pela época de semeadura das plantas de cobertura, realizado no outono, onde as condições eram de temperatura moderada e baixa radiação solar. O manejo efetuado das plantas de cobertura Cultura Agronômica, Ilha Solteira, v.24, n.2, p.157-166, 2015 
em um período curto se deve à necessidade de uso intensivo de uma mesma área pelo produtor de hortaliça, com vários ciclos culturais durante o ano, o que difere do produtor de grãos.

Verificando-se a Tabela 3, conclui que para a produção de massa fresca e seca da alface americana, houve respostas diferentes quanto ao tipo de consórcio. O consórcio crotalária + braquiária e o consórcio crotalária + milheto, apresentaram as melhores médias não diferindo significativamente entre si. O consórcio guandu + milheto superou o consórcio guandu + braquiária, quanto ao seu efeito na produção de massa fresca da alface, o que evidencia que o milheto exerceu melhor influência em relação à braquiária quanto à produção da alface, o guandu devido à baixa produção de massa seca, exerceu pouca influência no consórcio.

Os tratamentos com crotalária apresentaram as melhores médias para a produção de massa da alface, não diferindo significativamente entre si. Houve assim, possivelmente, uma sincronia entre a liberação de nutrientes pela crotalária e a época de maior exigência nutricional da alface, uma vez que a crotalária devido à baixa relação $\mathrm{C} / \mathrm{N}$, sofre rápida decomposição, interferindo positivamente no desempenho das culturas subsequentes (LOPES, 1994).

A vegetação espontânea e a adubação com Sulfato de Amônio (Tabela 3), foram os tratamentos que menos influenciaram o desenvolvimento da alface, apresentando as menores médias. A adubação com Sulfato de Amônio apresentou pouco efeito sobre o desenvolvimento da alface, possivelmente devido sua incorporação ter ocorrido três semanas antes do plantio da alface no canteiro, que devido a sua alta solubilidade, grande parte dos nutrientes já haviam sido liberados quando foi executado o plantio.

Tabela 3. Produção de massa fresca e seca e teor de clorofila da alface em função dos tratamentos.

\begin{tabular}{lccc}
\hline \multicolumn{1}{c}{ Tratamento } & Massa Fresca & $\begin{array}{c}\text { Massa Seca } \\
\end{array}$ & $\begin{array}{c}\text { Clorofila Total } \\
-------(\text { gramas/planta })------\end{array}$ \\
\hline Vegetação espontânea & $105,00 \mathrm{~d}^{*}$ & $6,75 \mathrm{~d}$ & $32,00 \mathrm{a}$ \\
Guandu + Braquiária & $278,25 \mathrm{c}$ & $18,97 \mathrm{~b}$ & $30,50 \mathrm{a}$ \\
Guandu + Milheto & $310,25 \mathrm{~b}$ & $20,1 \mathrm{~b}$ & $32,50 \mathrm{a}$ \\
Crotalária + Braquiária & $367,50 \mathrm{a}$ & $24,7 \mathrm{a}$ & $33,75 \mathrm{a}$ \\
Crotalária + Milheto & $382,52 \mathrm{a}$ & $25,1 \mathrm{a}$ & $34,25 \mathrm{a}$ \\
Adubação com Sulfato de & $127,00 \mathrm{~d}$ & $8,5 \mathrm{c}$ & $34,50 \mathrm{a}$ \\
Amônio & 3,03 & 3,11 & 11,01 \\
\hline C.V $(\%)$ & & &
\end{tabular}

*Médias seguidas de letras iguais na mesma coluna não diferem entre si (Tukey 5\% de probabilidade).

*Means followed by the same letters in column do not differ (Tukey at $5 \%$ of probability).

Por ser uma cultura de ciclo curto, a alface é muito exigente em nutrientes sendo importante a aplicação de adubos orgânicos para atender a demanda de nutrientes, assim, quanto mais rápida a disponibilidade desses nutrientes para a hortaliça, maior será sua taxa de desenvolvimento. 
A absorção dos nutrientes, advindos da mineralização dos adubos verdes, pela alface depende em grande parte, da sincronia entre a decomposição e mineralização dos resíduos vegetais e a época de maior exigência nutricional da cultura (FONTANÉTTI et al., 2006). Em experimento com várias cultivares de alface, Santi et al. (2010) obtiveram, uma produção de $400 \mathrm{~g}_{\text {planta }}{ }^{-1}$ com o uso de esterco bovino e adubação mineral. Peixoto Filho (2006), trabalhando com cultivos sucessivos de alface, com uso de esterco de ovino, na dose de $128,57 \mathrm{Mg} \mathrm{ha}^{-1}$, obteve uma produção máxima de $129,50 \mathrm{~g}$ planta $^{-1}$ no primeiro cultivo. A maior taxa de crescimento da alface, decorrente do pré-cultivo da crotalária é possivelmente associada às expressivas quantidades de potássio $(\mathrm{K})$ e $\mathrm{N}$ liberadas dos resíduos. Segundo Csizinsky e Schuster (1993), principalmente na fase inicial (0 a 30 dias) e de subsequente expansão das folhas externas (30 a 60 dias), a disponibilidade desses nutrientes induz um rápido e vigoroso desenvolvimento das plantas.

Quanto ao teor de clorofila total entre as folhas avaliadas (Tabela 3), não houve diferença significativa entre os tratamentos, possivelmente em função do mesmo local e época que todas as plantas de cobertura foram conduzidas, estando sujeitas as mesmas condições ambientais, consequentemente o teor de $\mathrm{N}$ presente nas folhas não foi o fator limitante na produção da alface, já que segundo Evans e Seemann (1989), cerca de $75 \%$ da quantidade de $\mathrm{N}$ está presente nas moléculas de clorofila e mais concentradamente no aparelho fotossintético, havendo uma forte relação entre a quantidade de $\mathrm{N}$ com taxas de fotossíntese máxima.

\section{CONCLUSÃO}

A partir dos resultados obtidos conclui-se que:

Os consórcios crotalária + milheto e crotalária + braquiária se destacaram na produção de massa seca e conferiram maior desenvolvimento da alface, o que mostra a viabilidade do uso desses consórcios em substituição à adubação mineral, na produção da alface.

\section{REFERÊNCIAS BIBLIOGRÁFICAS}

AlVARENGA, R. C.; COSTA, L. M.; MOURA FILHO, W.; REGAZZI, A. J. Características de alguns adubos verdes de interesse para a conservação e recuperação de solos. Pesquisa Agropecuária Brasileira, Brasília, v. 30, n. 2, p.175-185, 1995.

AMBROSANO, E. J; TRIVELIN, P. C. O; CANTARELLA'H.; AMBROSANO, G. M. B.; SCHAMMASS, E. A.; MURAOKA, T.; ROSSI, F. Nlabeled nitrogen from green manure and ammonium sulfate utilization by the sugarcane ratoon. Scientia Agricola, Piracicaba, v. 68, n. 3, p.361-368, 2011.

CALVO, C. L. Produtividade de fitomassa e relação C/N de monocultivos e consórcios de guandu, milheto e sorgo em três épocas de corte. Bragantia, Campinas, v. 69, n. 1, p.77-86, 2010 .

Cultura Agronômica, Ilha Solteira, v.24, n.2, p.157-166, 2015 
CARVAlHO, M. A. C.; SORATTO, R. P.; ATHAYDE, M. L. F.; SÁ, M. E. Produtividade do milho em sucessão a adubos verdes no sistema plantio direto e convencional. Pesquisa Agropecuária Brasileira, Brasília, v. 39, n. 1, p.47-53, 2004.

CSIZINSKI, A. A.; SCHUSTER, D. J. Impact of insecticide schedule, $\mathrm{N}$ and $\mathrm{K}$ rates and transplant container type on cabbage yield. Hortscience, Alexandria, v. 28, n. 4, p.299-302, 1993.

EVANS, J. R.; SEEMANN, J. R. The allocation of protein nitrogen in the Photosynthetic Apparatus: Costs, Consequences, and Control. In: BRIGGS, W.R. (ed). Photosynthetic. Liis. New York: W.R. BRIGGS (ed.), 1989. p. 183-205.

FERNANDES, M. F.; BARRETO, A. C.; EMÍDIO F. J. Fitomassa de adubos verdes e controle de plantas daninhas em diferentes densidades populacionais de leguminosas. Pesquisa Agropecuária Brasileira, Brasília, v. 34, n. 9, p.1593-1600, 1999.

FERREIRA, D. F. Sistemas para análise de variância para dados balanceados. Sisvar versão 5.1. Lavras: UFLA, 2007. Disponível em: <http://www.scielo.br/scielo.php?script=sci_nlinks\&ref=000083\&pid=S0006$8705201000020000800007 \& \operatorname{lng}=\mathrm{pt}>$. Acesso em: 15 mar. 2012.

FOnTANÉTTI, A.; CARVAlHO, G. J.; GOMES, L. A. A.; ALMEIDA, K.; MORAES, S. R. G.; TEIXEIRA, C. M. Adubação verde na produção orgânica de alface americana e repolho. Horticultura Brasileira, Brasília, v. 24, n. 2, p.146-150, 2006.

KISSMANN, K. G. Plantas infestantes e nocivas. São Paulo: BASF, 1997. 825 p.

KUKI, K. N.; OLIVA M. A.; GOMES F. P.; COSTA A. C. Avaliação da eficiência do dimetilsulfóxido na extração de pigmentos foliares de Schinus terebenthifolius e Cocos nucifera. In: CONGRESSO BRASILEIRO DE FISIOLOGIA VEGETAL e CONGRESSO LATINO-AMERICANO DE FISIOLOGIA VEGETAL, 10. e 7., 2005, Recife. Anais... Recife: SBFV, 2005. 1 CD-ROM.

LOPES, A. S. Manejo: Aspectos Químicos. In: PEREIRA, V. P. FERREIRA, M. E.; CRUZ, M. C. P., (ed.). Solos Altamente Susceptíveis à Erosão. Jaboticabal: FCAV UNESP / SBCS, 1994. p.79-111.

NEGRINI, A. C. A. Desempenho de alface (Lactuca sativa L.) consorciada com diferentes adubos verdes. 2007. 113 f. Dissertação (Mestrado em Agronomia - Fitotecnia) - Escola Superior de Agricultura Luiz de Queiroz, Universidade de São Paulo, Piracicaba, 2007.

Cultura Agronômica, Ilha Solteira, v.24, n.2, p.157-166, 2015 
NETTO, D. A. M.; BONAMIGO, L. A. Milheto: característica da espécie e uso. In: NETTO, D. A. M.; DURÕES, F. O. M. (Eds.). Milheto: tecnologias de produção e agronegócio. (Ed.) Brasília: Embrapa Informações tecnológicas, 2005. p.17-33.

OLIVEIRA, T. K.; CARVALHO, G. J.; MORAES, R. N. S. Plantas de cobertura e seus efeitos sobre o feijoeiro em plantio direto. Pesquisa Agropecuária Brasileira, Brasília, v. 37, n. 8, p.1079-1087, 2002.

PEIXOTO FILHO, J. U. Produtividade de alface com o uso de diferentes fontes de matéria orgânica e efeito ma fertilidade do solo. 2006. 132 f. Dissertação (Mestrado em Ciência do Solo) - Universidade Federal Rural de Pernambuco, Recife, 2006.

PERIN, A.; LIMA, E. A.; PEREIRA, M. G.; TEIXEIRA, M. G.; GUERRA, J. G. M. Efeitos de coberturas vivas com leguminosas perenes sobre a umidade e temperatura do solo. Agronomia, Seropédica, v. 38, n. 1, p.27-31, 2004.

SANTI, A; CARVAlHO, M. A. C; CAMPOS, O. R; SIlVA, A. F; ALMEIDA, J. L; MONETIRO, S. Ação de material orgânico sobre a produção e características comerciais de cultivares de alface. Horticultura Brasileira, Brasília, v. 28, n. 1, p.87-90, 2010.

SILVA, T. O.; MENEZES, R. S. C. Adubação orgânica da batata com esterco e, ou, Crotalaria juncea. II - Disponibilidade de N, P e K no solo ao longo do ciclo de cultivo. Revista Brasileira de Ciência do Solo, Viçosa, v. 31, n. 1, p.51-61, 2007.

SUZUKI, L. E. A. S.; ALVES, M. C. Fitomassa de plantas de cobertura em diferentes sucessões de culturas e sistemas de cultivo. Bragantia, Campinas, v. 65, n. 1, p.121-127, 2006.

TEODORO, R. B.; OliveIRA, F. L.; SILVA, D. M. N.; FAVERO, C. Produção de Fitomassa e Acúmulo de Nutrientes em Leguminosas Arbustivas, no Município de Turmalina-MG. Revista Brasileira de Agroecologia, Cruz Alta, v. 4, n. 2, p.4520-4523, 2009.

WELLBURN, A. R. The spectral determination of chlorophylls $a$ and $b$, as well as total carotenoids, using various solvents with spectrophotometers of different resolution. Journal of Plant Physiology, Lancaster, v. 144, n. 3, p.307-313, 1994. 